\title{
Value and Level of Plasma Homocysteine in Patients With Angina Pectoris Undergoing Coronary Angiographic Study
}

\author{
Han-Tan ChaI, ${ }^{1} \mathrm{MD}$, Yung-Lung Chen, ${ }^{1 *} \mathrm{MD}$, Sheng-Ying Chung, ${ }^{1} \mathrm{MD}$, Tzu-Hsien Tsai, ${ }^{1} \mathrm{MD}$, \\ Cheng-Hsu YANG, ${ }^{1}$ MD, Huang-Chung Chen, ${ }^{1}$ MD, Pei-Hsun Sung,${ }^{1}$ MD, Cheuk-Kwan Sun, ${ }^{2}$ MD, \\ Li-Teh Chang, ${ }^{3} \mathrm{PhD}$, Chang-Qing FAn, ${ }^{4 \dagger} \mathrm{MD}$, and Hon-Kan YIP, ${ }^{1} \mathrm{MD}$
}

\begin{abstract}
SUMMARY
This study tested whether the plasma level of total homocysteine (tHcy) was predictive of obstructive coronary artery disease (CAD) and clinical outcome in patients undergoing coronary angiographic (CAG) study. From September 2002 to October 2004, 1,305 consecutive patients with angina pectoris undergoing CAG study were consecutively enrolled. Blood samples were prospectively collected to assess the plasma level of tHcy from each patient before catheterization. Of these 1305 patients, 676 (51.8\%) had multivessel disease (group 1), 367 (28.1\%) had single-vessel disease (group 2), and $262(20.1 \%)$ had normal coronary artery or insignificant coronary artery disease (group 3 ). The plasma level of tHcy was notably higher in group 1 than in groups 2 and $3(11.6 \pm 4.4$ versus $10.9 \pm 4.0$ versus $10.4 \pm 3.8, P<$ 0.001). Univariate binary logistic regression analysis demonstrated that the plasma tHcy level was strongly associated with multiple-vessel disease (MVD) (defined as $\geq 2$ vessel disease) $(P<0.001)$. Multivariate binary logistic regression analysis showed that tHcy level, fasting blood sugar, diabetes mellitus, and age were significantly and independently predictive of MVD (all $P<0.03$ ). Univariate Cox regression analysis demonstrated that thcy level was predictive of longterm mortality $(P=0.042)$. However, the tHcy level was not an independent predictor of long-term mortality on multivariate Cox regression analysis $(\mathrm{P}>0.05)$. The results of our study support the hypothesis that tHcy level is an independent predictor of MVD in patients with chest pain undergoing CAG study. Conversely, our study did not support the tHcy level as an independent predictor of long-term mortality in this clinical setting. (Int Heart J 2011; 52: 280-285)
\end{abstract}

Key words: Angina pectoris, Coronary artery disease, Plasma tHcy level, Long-term clinical outcome

$\mathrm{D}$ espite the implementation of primary and secondary strategic management, coronary artery disease (CAD) remains the leading cause of death worldwide. ${ }^{1,2)}$ Interestingly, while traditional CAD risk factors have been suggested to be one of the most useful predictors of future CAD risk, they can only predict less than half of future cardiovascular events and cardiovascular disease. ${ }^{3,4)}$ Of these novel CAD risk factors, $\mathrm{C}$-reactive protein (CRP) is believed to be particularly important in predicting future cardiovascular events because not only is CRP a biomarker, but it is also found to directly participate in the initiation and propagation of arterial atherosclerosis. ${ }^{5-13)}$ In contrast, the reliability of plasma total homocysteine (tHcy) in either predicting future cardiovascular events or assessing the severity of CAD is still controversial because of inconsistent results from previous studies. ${ }^{14-16)}$ Therefore, to test the correlation between the plasma level of tHcy and severity of CAD as well as the clinical outcome in patients with chest pain undergoing coronary angiographic study, the current study consecutively enrolled 1305 patients who were followed-up for more than one year.

\section{MeTHODS}

Study population and inclusion criteria: For the purposes of this study, the plasma tHcy level of all patients who had angina pectoris undergoing cardiac catheterization was prospectively measured. A single blood sample was obtained following vascular puncture and before coronary angiography in the cardiac catheterization laboratory. To avoid other variables that could potentially influence the plasma concentration of tHcy, we excluded patients with a history of consumption of folic acid or vitamin B supplements, history of folic acid or vitamin B complex deficiency, renal insufficiency (creatinine $\geq 1.5 \mathrm{mg} / \mathrm{dL}$ ), and fasting less than 4.5 hours before blood sampling. Between September 2002 and October 2004, we prospectively recruited 1,305 consecutive patients of various ages who underwent coronary angiographic study due to chest pain accord-

From the ${ }^{1}$ Division of Cardiology, Department of Internal Medicine and ${ }^{2}$ Division of General Surgery, Department of Surgery, Kaohsiung Chang Gung Memorial Hospital and Chang Gung University College of Medicine, Kaohsiung, ${ }^{3}$ Basic Science, Nursing Department, Meiho University, Pingtung, Taiwan, R.O.C. and ${ }^{4}$ Division of Cardiology, Department of Internal Medicine, Xiamen Chang Gung Memorial Hospital, Xiamen, P.R.O.C.

"This author and the first author contributed equally to this work.

This author and the correspondence author contributed equally to this work.

Address for correspondence: Hon-Kan Yip, MD, Division of Cardiology, Department of Internal Medicine, Kaohsiung Chang Gung Memorial Hospital and Chang Gung University College of Medicine, 123 Ta Pei Road, Niao Sung Hsiang, Kaohsiung Hsien, 83301, Taiwan, R.O.C.

Received for publication March 3, 2011

Revised and accepted May 30, 2011. 
ing to the criteria at our hospital. Of these 1305 patients, 676 $(51.8 \%)$ had multivessel disease (group 1), 367 (28.1\%) had single-vessel disease (group 2), and 262 (20.1\%) had normal coronary arteries or insignificant coronary artery disease (group 3 ). The study protocol was approved by the Institutional Review Committee on Human Research at our institution.

Blood sampling and laboratory investigations: One blood sample was obtained from each patient in the catheterization laboratory prior to coronary angiographic examination. After immediate centrifugation of the blood sample, the plasma was stored at $-4^{\circ} \mathrm{C}$ and then the tHcy level was determined by Fluorescence Polarization immunoassay (FPIA) (Abbott IMx, Abbott Diagnostics) within 6 hours. ${ }^{17,18)}$ The lower detection limit of this test was $0.00 \mu \mathrm{mol} / \mathrm{L}$ and a plasma tHcy level $>12$ $\mu \mathrm{mol} / \mathrm{L}$ was considered above the normal limit in our laboratory. Assessment of intraindividual variability in plasma tHcy levels showed a mean intra-assay coefficient of variance of $3.35 \%$.

Angiographic analysis and definitions: Quantitative angiographic analysis of the degree of coronary artery luminal stenosis and the reference lumen diameter was conducted using a digital edge-detection algorithm (DUQUE System) by selecting end-diastolic frames to demonstrate stenosis in its most severe and non-foreshortened projection. ${ }^{19)}$ With the contrastfilled guiding catheter serving as the calibration standard, the reference and minimal lumen diameters were determined before and after angioplasty. Single-vessel disease was defined as stenoses of $>50 \%$ in 1 major epicardial coronary artery. Multivessel disease was defined as stenoses of $>50 \%$ in $\geq 2$ major epicardial coronary arteries. Body mass index (BMI) was defined as body weight in kilograms divided by the square of body height in meters $\left(\mathrm{kg} / \mathrm{m}^{2}\right)$. A higher plasma concentration of tHcy was defined as one above the median level (ie, 10.29 $\mu \mathrm{mol} / \mathrm{L})$, whereas a lower plasma level was defined as one equal or less than the median level (ie, $10.29 \mu \mathrm{mol} / \mathrm{L}$ ).

Data collection: Detailed in-hospital and follow-up data including age, gender, coronary risk factors, BMI, concentrations of serum creatinine and plasma tHcy, number of diseased vessels, and the incidences of percutaneous coronary intervention (PCI) and coronary artery bypass surgery (CABG) were obtained. In-hospital and long-term mortality were recorded during hospitalization and follow-up in our outpatient department. These data were collected prospectively and entered into a digital database.

Statistical analysis: Data are expressed as the mean \pm SD. Differences in continuous variables were analyzed by independent $t$ test and categorical variables by the chi-square test. Continuous variables among 3 groups were compared using one-way ANOVA followed by the Bonferroni multiple comparison procedure. The baseline variables were used for univariate analysis. Univariate and multivariate stepwise binary logistic regression analyses were utilized for assessing independent predictors of multiple vessel disease, while univariate and multivariate stepwise Cox proportional hazards regression analyses were adopted for identifying independent predictors of long-term mortality. Kaplan-Meier analysis was used for determining event-free survival. Statistical analysis was performed using SPSS statistical software for Windows version 13 (SPSS for Windows, version 13; SPSS Inc., IL, USA). A two-sided $P$ value less than 0.05 was considered to be statistically significant.

\section{RESULTS}

Baseline characteristics, angiographic findings, and incidence of coronary artery intervention of 1,305 study patients (Table I): The BMI and the incidence of previous stroke did not differ among group 1 (multivessel disease), group 2 (single-vessel disease), and group 3 (normal insignificant coronary artery disease). There was no difference in age between groups 2 and 3, however, group 1 was significantly older than groups 2 and 3 . The incidences of male gender and previous myocardial infarction were similar between groups 1 and 2, but these two parameters were higher in these two groups than in group 3 .

The incidence of current smoking did not differ between groups 1 and 2 and it showed no difference in group 1 as compared to group 3. However, it was significantly higher in group 2 than in group 3 . The incidences of diabetes mellitus and hypertension were remarkably higher in group 1 than in groups 2 and 3 , but there were no differences between groups 2 and 3 . Although the serum total cholesterol level was similar among the 3 groups, the incidence of statin therapy was notably higher in groups 1 and 2 than in group 3.

The levels of plasma tHcy and fasting blood sugar did not differ between groups 2 and 3 , but they were significantly lower in groups 2 and 3 than in group 1. Furthermore, the serum

Table I. Baseline Characteristics, Angiographic Results, and Incidence of Coronary Intervention of 1,305 Patients

\begin{tabular}{|c|c|c|c|c|}
\hline Variable & $\begin{array}{l}\text { Group } 1^{*} \\
(n=676)\end{array}$ & $\begin{array}{l}\text { Group } 2^{*} \\
(n=367)\end{array}$ & $\begin{array}{l}\text { Group } 3^{*} \\
(n=262)\end{array}$ & $P$ \\
\hline Age (years) & $63.6 \pm 10.0^{\mathrm{a}}$ & $61.7 \pm 10.4^{\mathrm{b}}$ & $61.5 \pm 10.2^{b}$ & 0.002 \\
\hline Male gender $(\%)$ & $75.6 \%(511)^{\mathrm{a}}$ & $78.5 \%(288)^{\mathrm{a}}$ & $66.0 \%(173)^{\mathrm{b}}$ & 0.001 \\
\hline BMI $\left(\mathrm{kg} / \mathrm{m}^{2}\right)$ & $25.9 \pm 3.8$ & $26.2 \pm 3.6$ & $26.5 \pm 4.1$ & 0.112 \\
\hline Current smoking (\%) & $28.8 \%(195)^{\mathrm{ab}}$ & $33.8 \%(124)^{\mathrm{a}}$ & $23.7 \%(62)^{b}$ & 0.022 \\
\hline Diabetes mellitus (\%) & $38.3 \%(259)^{\mathrm{a}}$ & $26.2 \%(96)^{\mathrm{b}}$ & $19.5 \%(51)^{b}$ & $<0.001$ \\
\hline Hypertension (\%) & $61.7 \%(414)^{\mathrm{a}}$ & $52.9 \%(194)^{\mathrm{b}}$ & $53.8 \%(141)^{\mathrm{b}}$ & 0.014 \\
\hline Statin use $(\%)^{\dagger}$ & $57.4 \%(388)^{\mathrm{a}}$ & $53.4 \%(196)^{\mathrm{a}}$ & $28.2 \%(74)^{\mathrm{b}}$ & $<0.001$ \\
\hline Previous stroke (\%) & $7.7 \%(52)$ & $6.5 \%(24)$ & $6.5 \%(17)$ & 0.712 \\
\hline $\begin{array}{l}\text { Old myocardial in- } \\
\text { farction }(\%)\end{array}$ & $18.8 \%(127)^{\mathrm{a}}$ & $21.3 \%(78)^{\mathrm{a}}$ & $11.1 \%(29)^{\mathrm{b}}$ & 0.003 \\
\hline $\begin{array}{l}\text { Homocysteine level } \\
\qquad(\mu \mathrm{mol} / \mathrm{L})\end{array}$ & $11.55 \pm 4.37^{\mathrm{a}}$ & $10.87 \pm 3.99^{b}$ & $10.38 \pm 3.80^{\mathrm{b}}$ & $<0.001$ \\
\hline $\begin{array}{l}\text { Total cholesterol level } \\
\quad(\mathrm{mg} / \mathrm{dL})\end{array}$ & $184.2 \pm 42.6$ & $179.2 \pm 36.3$ & $178.5 \pm 36.5$ & 0.057 \\
\hline $\begin{array}{l}\text { Fasting blood sugar } \\
\qquad(\mathrm{mg} / \mathrm{dL})\end{array}$ & $146.6 \pm 101.8^{\mathrm{a}}$ & $126.6 \pm 51.1^{\mathrm{b}}$ & $122.8 \pm 60.3^{b}$ & $<0.001$ \\
\hline $\mathrm{WBC}\left(\times 10^{3} / \mathrm{mL}\right)$ & $7.3 \pm 2.8$ & $7.1 \pm 2.4$ & $7.1 \pm 5.2$ & 0.699 \\
\hline Creatinine (mg/dL) & $1.1 \pm 0.5^{\mathrm{a}}$ & $1.1 \pm 0.5^{\mathrm{ab}}$ & $1.0 \pm 0.4^{\mathrm{b}}$ & 0.003 \\
\hline Unstable angina $(\%)$ & $51.8 \%(350)^{\mathrm{a}}$ & $46.3 \%(170)^{\mathrm{a}}$ & $12.6 \%(33)^{\mathrm{b}}$ & $<0.001$ \\
\hline PCI (\%) & $77.7 \%(525)^{\mathrm{a}}$ & $68.1 \%(250)^{\mathrm{b}}$ & $0 \%(0)^{\mathrm{c}}$ & $<0.001$ \\
\hline CABG $(\%)$ & $15.4 \%(104)^{\mathrm{a}}$ & $3.3 \%(12)^{\mathrm{b}}$ & $0 \%(0)^{\mathrm{c}}$ & $<0.001$ \\
\hline $\begin{array}{l}\text { Long-term mortality } \\
\qquad(\%)^{+}\end{array}$ & $3.3 \%(22)^{\mathrm{a}}$ & $2.7 \%(10)^{\mathrm{a}}$ & $0 \%(0)^{\mathrm{b}}$ & 0.014 \\
\hline CV death & $1.3 \%(9)$ & $1.1 \%(4)$ & $0 \%(0)$ & \\
\hline Non-CV death & $1.9 \%(13)$ & $1.6 \%(6)$ & $0 \%(0)$ & \\
\hline
\end{tabular}

Data are expressed as mean $\pm \mathrm{SD}$ or $\%(n)$ of patients. ${ }^{*}$ Group 1 , multi-vessel disease; Group 2, single-vessel disease; Group 3, normal or insignificant coronary artery disease. Statin use defined as statin therapy $\geq 5$ days prior to blood sampling. $\neq$ Long-term mortality mean follow-up time $=365.9 \pm 205.8$ days. $\mathrm{BMI}$ indicates body mass index; $\mathrm{CV}$, cardiovascular; $\mathrm{CABG}$, coronary artery bypass surgery; PCI, percutaneous coronary intervention; and WBC, white blood cell count. Letters $\left({ }^{\mathrm{a}, \mathrm{b}, \mathrm{c}}\right)$ indicate significant difference (at 0.05 level) by Bonferroni's multiple comparison procedure. 
Table II. Impact of Higher Plasma Level of Homocysteine on Angiographic Results, Incidence of Coronary Artery Intervention, and Clinical Outcome of 1,305 Patients

\begin{tabular}{|c|c|c|c|}
\hline Variable & $\begin{array}{l}\text { Higher tHcy } \\
\quad(n=652)\end{array}$ & $\begin{array}{l}\text { Lower tHcy }^{*} \\
\quad(n=653)\end{array}$ & $P$ \\
\hline ge (years) & $64.1 \pm 10.2$ & $61.2 \pm 10.0$ & $<0.001$ \\
\hline Male gender $(\%$ & $81.7 \%(533)$ & $67.2 \%(439)$ & $<0.001$ \\
\hline BMI $\left(\mathrm{kg} / \mathrm{m}^{2}\right)$ & $26.0 \pm$ & $26.2 \pm 3.8$ & 0.592 \\
\hline urrent smoking (\%) & $32.1 \%(209)$ & $26.3 \%(172)$ & 0.023 \\
\hline iabetes n & 9) & 30.2 & 0.462 \\
\hline Hypertens & $60.1 \%$ & $54.7 \%$ & 0.046 \\
\hline Statin use $(\%)^{\dagger}$ & $49.4 \%(322)$ & $51.5 \%(336)$ & 0.455 \\
\hline Previous str & $8.7 \%$ & $5.5 \%$ & 0.023 \\
\hline Old myocardial il & $20.1 \%(131)$ & $15.8 \%(103)$ & 0.042 \\
\hline Cholesterol le & $178.3 \pm 37.2$ & $184.9 \pm 42.0$ & 0.003 \\
\hline Fasting blood sugar $(\mathrm{m}$ & $132.3 \pm 59.0$ & $139.9 \pm 101.4$ & 0.107 \\
\hline $\mathrm{WBC}\left(\times 10^{3} / \mathrm{mL}\right)$ & $7.3 \pm 3.8$ & $7.1 \pm 2.7$ & 0.270 \\
\hline Creatinine $(\mathrm{mg} / \mathrm{dL}$ & $1.3 \pm 0.6$ & $1.0 \pm 0.3$ & $<0.001$ \\
\hline Unstable angina $(c$ & $43.3 \%(282)$ & $41.5 \%(271)$ & 0.522 \\
\hline Multivessel disease $(\%)^{\frac{*}{*}}$ & $57.4 \%(374)$ & $46.2 \%(302)$ & $<0.001$ \\
\hline $\mathrm{PCI}(\%)$ & $61.8(403)$ & $57.6 \%(376)$ & 0.119 \\
\hline CABG $(\%)$ & $8.4 \%(55)$ & $9.3 \%(61)$ & 0.565 \\
\hline $\begin{array}{l}\text { Repeated coronary intervention } \\
(\%)\end{array}$ & $4.3 \%(28)$ & $3.7 \%(24)$ & 0.568 \\
\hline Long-term mortality $(\%)$ & $3.4 \%(22)$ & $1.5 \%(10)$ & 0.031 \\
\hline
\end{tabular}

Data are expressed as mean \pm SD or \% ( $n)$ of patients. "Higher tHcy group defined as > median level $(10.29 \mu \mathrm{mol} / \mathrm{L})$ of total homocysteine (tHcy) and lower tHcy group defined as $\geq$ median level $(10.29 \mu \mathrm{mol} / \mathrm{L})$ of tHcy. Statin use defined as statin was used $\geq 5$ days prior to blood sampling. "Multivessel disease defined as $\geq 2$ obstructive coronary artery disease. "Long-term mortality mean follow-up time $=365.9 \pm 205.8$ days. BMI indicates body mass index; CABG, coronary artery bypass surgery; PCI, percutaneous coronary intervention; and WBC, white blood cell count.

Table III. Correlation Between Homocysteine Level and Enrollment Variables in Table I

\begin{tabular}{lcr}
\hline Variable & $\mathrm{R}$ & \multicolumn{1}{c}{$P^{*}$} \\
\hline Age & 0.145 & $<0.001$ \\
Male gender & 0.191 & $<0.001$ \\
Current smoking & 0.07 & 0.011 \\
Previous stroke & 0.071 & 0.011 \\
Old myocardial infarction & 0.066 & 0.017 \\
Multivessel disease & 0.106 & $<0.001$ \\
Creatinine level & 0.335 & $<0.001$ \\
Cholesterol level & -0.09 & 0.001 \\
\hline
\end{tabular}

" $P$ by Pearson's correlation analysis. PCI indicates percutaneous coronary intervention.

level of creatinine was substantially lower in group 3 than in group 1. However, this parameter did not differ between groups 1 and 2 or between groups 2 and 3. Moreover, the white blood cell count was similar among the 3 groups.

The prevalence of unstable angina was markedly higher in groups 1 and 2 than in group 3, but it showed no difference between groups 1 and 2. Group 3 patients did not receive any PCI or CABG. However, the incidences of PCI and CABG were notably higher in group 1 than in groups 2 and 3 , and higher in group 2 than in group 3 . The cumulative long-term mortality (combined noncardiovascular and cardiovascular death) did not differ between groups 1 and 2, but it was significantly higher in groups 1 and 2 than in group 3 .
Table IV. Univariate Binary Logistic Regression Analysis for Multivessel Disease

\begin{tabular}{lccr}
\hline Variable & Odds Ratio & 95\% CI & \multicolumn{1}{c}{$P$} \\
\hline Age & 1.019 & $1.008-1.030$ & 0.001 \\
Diabetes mellitus & 2.037 & $1.600-2.592$ & $<0.001$ \\
Hypertension & 1.387 & $1.113-1.728$ & 0.004 \\
Homocysteine level & 1.053 & $1.025-1.082$ & $<0.001$ \\
Creatinine level & 1.471 & $1.118-1.935$ & 0.006 \\
Total cholesterol level & 1.003 & $1.001-1.006$ & 0.017 \\
Fasting blood sugar & 1.005 & $1.003-1.007$ & $<0.001$ \\
\hline
\end{tabular}

CI indicates confidence interval.

Table V. Multivariate Binary Logistic Regression Analysis of Multivessel Disease

\begin{tabular}{lccc}
\hline Variable & Odds Ratio & $95 \%$ CI & $P$ \\
\hline Fasting blood sugar & 1.002 & $1.000-1.004$ & 0.029 \\
Diabetes mellitus & 1.761 & $1.315-2.358$ & 0.001 \\
Homocysteine level & 1.038 & $1.006-1.072$ & 0.019 \\
Age & 1.023 & $1.010-1.037$ & 0.001 \\
\hline
\end{tabular}

CI indicates confidence interval.

Impact of higher plasma level of total homocysteine on angiographic findings, incidence of coronary artery intervention, and clinical outcome of 1,305 patients (Table II): To investigate whether the plasma tHcy level was predictive of the severity of obstructive CAD and long-term clinical outcome, the patients were categorized into a higher tHcy group [defined as those patients with tHcy > median level $(10.29 \mu \mathrm{mol} / \mathrm{L})]$ and a lower tHcy group [defined as those patients with tHcy $\leq$ median level $(10.29 \mu \mathrm{mol} / \mathrm{L})]$. The BMI, level of fasting blood sugar, white blood cell count, and the incidences of diabetes mellitus, statin use, unstable angina, PCI, and CABG were similar between the two groups. However, the mean age of patients in the higher tHcy group was higher than that in the lower tHcy group. In addition, the incidences of male gender, hypertension, current smoking, previous stroke, and old myocardial infarction were notably higher in the higher tHcy group compared with those in the lower tHcy group. Moreover, the serum creatinine level was significantly higher, whereas the total cholesterol level was notably lower in the higher tHcy group than in the lower tHcy group. Furthermore, as expected, the incidences of multiple-vessel disease and long-term mortality were remarkably higher in the higher tHcy group than in the lower tHcy group. Correlation between homocysteine level and enrollment variables (Table III): To assess the correlation between baseline variables and plasma tHcy level, Pearson's correlation analysis was performed in the current study. The results showed that age, male gender, serum creatinine concentration, and multiple-vessel disease were the strongest factors correlated with an increased plasma tHcy concentration. Moreover, current smoking, previous stroke, and old myocardial infarction were also significantly correlated with the plasma tHcy level. On the other hand, a higher total cholesterol level was inversely correlated to an increased plasma level of tHcy.

Binary logistic regression analysis for multiple-vessel disease (Tables IV and V): To determine whether the plasma level of 
Table VI. Univariate Cox Regression Analysis on Long-Term Mortality

\begin{tabular}{lcrr}
\hline Variable & Hazard Ratio & $95 \%$ CI & \multicolumn{1}{c}{$P$} \\
\hline Age & 1.078 & $1.036-1.121$ & $<0.001$ \\
Body mass index & 0.880 & $0.815-0.951$ & 0.001 \\
Previous stroke & 2.885 & $1.187-7.011$ & 0.019 \\
Serum creatinine & 1.526 & $1.204-1.934$ & 0.001 \\
Fasting blood sugar & 1.003 & $1.001-1.004$ & $<0.001$ \\
Homocysteine level & 2.172 & $1.027-4.590$ & 0.042
\end{tabular}

$\mathrm{CI}$ indicates confidence interval.

Table VII. Multivariate Cox Regression Analysis on Long-Term Mortality

\begin{tabular}{lccc}
\hline Variable & Hazard Ratio & $95 \%$ CI & $P$ \\
\hline Fasting blood sugar & 1.003 & $1.001-1.005$ & 0.001 \\
Serum creatinine & 2.057 & $1.351-3.133$ & 0.001 \\
Body mass index & 0.839 & $0.746-0.942$ & 0.003 \\
Age & 1.058 & $1.012-1.106$ & 0.012 \\
\hline
\end{tabular}

CI indicates confidence interval.

tHcy was independently predictive of multiple-vessel disease, univariate and multiple binary logistic regression analyses were performed. Univariate analysis revealed that plasma level of tHcy, diabetes mellitus, and fasting blood sugar were most strongly predictive of multiple-vessel disease. In addition, age, hypertension, and serum levels of creatinine and total cholesterol were also significantly predictive of multiple-vessel disease.

Multivariate binary logistic regression analysis showed that both age and diabetes mellitus were the most strongly independent predictors of multiple-vessel disease. Furthermore, plasma homocysteine level and fasting blood sugar were also significantly and independently predictive of multiple-vessel disease.

Kaplan-Meier and Cox regression analysis for long-term mortality (Tables VI and VII): This study was designed to determine whether the plasma level of tHcy was independently predictive of long-term mortality. Univariate Cox regression analysis for long-term mortality demonstrated that age, BMI, previous stroke, fasting blood sugar, and serum creatinine levels were remarkably predictive of long-term mortality. However, the plasma level of tHcy was weakly but significantly correlated with long-term mortality.

Multivariate Cox regression analysis for long-term mortality demonstrated that only age, BMI, fasting blood sugar, and serum creatinine levels were significantly and independently predictive of long-term mortality.

Kaplan-Meier analysis (Figure) for event-free survival showed a significantly lower long-term survival rate in patients with a higher plasma tHcy concentration compared with those with a lower plasma tHcy level.

\section{Discussion}

This study, which investigated the impact of the plasma level of tHcy on patients with angina pectoris undergoing coronary angiographic study, provided several striking implications. First, a higher plasma level of tHcy was a significant in-

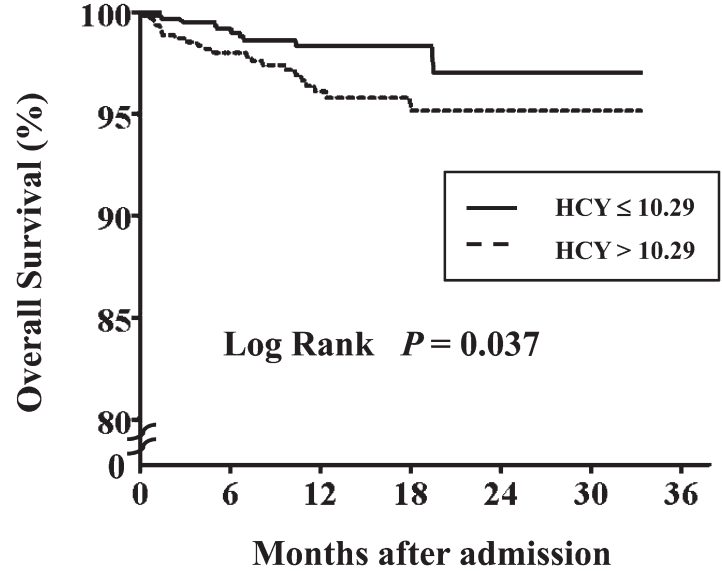

Figure. Kaplan-Meier analysis of free-survival rate. Higher tHcy group: Plasma tHcy $>10.29 \mu \mathrm{mol} / \mathrm{L}$; Lower tHcy group: Plasma tHcy $\leq 10.29$ $\mu \mathrm{mol} / \mathrm{L}$.

dependent predictor of multiple vessel disease. Second, the plasma level of tHcy was not an independent predictor of longterm mortality.

Similar to CRP, ${ }^{11-13)}$ the plasma total tHcy level has been shown to be a new risk factor for CAD. ${ }^{14,15,20)}$ Regardless of the underlying etiology or mechanisms, plasma tHcy has been revealed to be strongly correlated with obstructive $\mathrm{CAD},{ }^{7,20)}$ restenosis, major adverse cardiac events after percutaneous coronary angioplasty, ${ }^{21)}$ and all-cause mortality. ${ }^{22,23)}$ Additionally, the association between increased plasma tHcy level and the severity of atherosclerosis has been investigated. ${ }^{18)}$ Furthermore, the link between increased plasma tHcy level and progression of atherosclerosis has been previously reported. ${ }^{24)}$ Still another study has even shown that plasma tHcy level predicts mortality independent of traditional risk factors and CRP levels in patients with angiographically defined coronary artery disease. ${ }^{25)}$ One of the important findings in the current study is that the plasma tHcy level was remarkably higher in patients with significant obstructive CAD than in those without significant obstruction. The most important finding in the present study is that multivariate binary logistic regression analysis demonstrated that plasma tHcy was independently predictive of significantly obstructive CAD in patients with experience of angina pectoris. Interestingly, the majority of these patients who had significant obstruction of CAD received PCI. The results of the present study, therefore, are consistent with those of previous studies. ${ }^{7,14-21)}$

Interestingly, despite the consistency of the finding in the current study that links plasma level of tHcy with CAD, the impact of plasma tHcy level on long-term mortality was unremarkable after multivariate Cox regression analysis. In this way, our findings corroborated those of previous studies showing that plasma tHcy is not independently predictive of longterm clinical outcome. ${ }^{7,16,26)}$ In contrast to our findings and also those of previous studies, ${ }^{7,16,26)}$ some previous investigations have previously shown that the plasma level of tHcy is a significant predictor of long-term outcome regardless of the disease entity. ${ }^{22,23,27)}$ The cause of the discrepancy between previous findings and those from our and other studies remains 
uncertain. Possible causes are as follows: First, plasma tHcy level has been shown to be associated with both genetic and nutritional factors, as well as dietary habits. ${ }^{28)}$ Second, an increased plasma level of tHcy can be found in subjects with chronic alcoholic consumption, impairment of liver function, and those with altered methionine and homocysteine metabolism. ${ }^{29)}$ Third, the plasma level of tHcy has been shown to be strongly correlated with age, gender, smoking, serum folate, vitamin B12, and renal function. ${ }^{22,30-32)}$ Interestingly, in the present study, we also found that age, gender, current smoking, and the serum level of creatinine were strongly correlated with plasma tHcy level. Accordingly, the findings of the current investigation corroborate those of previous studies, ${ }^{30-32)}$ and further confirm that an increased plasma level of tHcy is multifactorial. ${ }^{22,30-33)}$ Finally, methodological problems have been reported to contribute to uncertain determination of the strength of these relationships, especially those among an elevated plasma tHcy level and traditional risk factors. ${ }^{34)}$

Undoubtedly, traditional CAD risk factors have been recognized as independent predictors of long-term untoward clinical outcomes in study subjects with or without chest pain syndrome. ${ }^{35-38)}$ With the recruitment of a large patient population, the present study further shows that the plasma level of tHcy, age, BMI, fasting blood sugar, and creatinine levels were independently predictive of long-term mortality. Therefore, our findings reinforce those of previous studies. ${ }^{35-38)}$

This study has several limitations. First, although it demonstrates that plasma tHcy was an independent predictor of obstructive $\mathrm{CAD}$, the mechanism underlying the role of plasma tHcy in endothelial dysfunction and propagation of coronary atherosclerosis and obstruction remains uncertain. Second, the endpoint of this study was designed for a clinical follow-up rather than routinely for an angiographic follow-up. Therefore, the number of patients who required repeated coronary intervention may be underestimated. Finally, only the correlation between the incidence of unstable angina rather than the plaque instability and plasma tHcy level was investigated.

In conclusion, plasma level of tHcy was independently predictive of MVD but it was not an independent predictor of long-term outcome in patients with angina pectoris undergoing coronary angiographic study.

\section{REFERENCES}

1. Reddy KS, Yusuf S. Emerging epidemic of cardiovascular disease in developing countries. Circulation 1998; 97: 596-601. (Review)

2. Fox CS, Evans JC, Larson MG, Kannel WB, Levy D. Temporal trends in coronary heart disease mortality and sudden cardiac death from 1950-1999: the Framingham Heart Study. Circulation 2004; 110: 522-7.

3. Grover SA, Coupal L, Hu XP. Identifying adults at increased risk of coronary disease. How well do the current cholesterol guidelines work? JAMA 1995; 274: 801-6.

4. Wilson PW, D'Agostino RB, Levy D, Belanger AM, Silbershatz H, Kannel WB. Prediction of coronary heart disease using risk factor categories. Circulation 1998; 97: 1837-47.

5. Ridker PM, Rifai N, Pfeffer MA, et al. Inflammation, pravastatin, and the risk of coronary events after myocardial infarction in patients with average cholesterol levels. Cholesterol and Recurrent Events (CARE) Investigators. Circulation 1998; 98: 839-44.

6. Haverkate F, Thompson SG, Pyke SD, Gallimore JR, Pepys MB. Production of C-reactive protein and risk of coronary events in stable and unstable angina. European Concerted Action on Thrombosis and Disabilities Angina Pectoris Study Group. Lancet 1997; 349: 462-6.

7. Eikelboom JW, Lonn E, Genest J Jr, Hankey G, Yusuf S. Homocyst(e) ine and cardiovascular disease: a critical review of epidemiologic evidence. Ann Intern Med 1999; 131: 363-75. (Review)

8. Hulthe J, McPheat W, Samnegård A, Tornvall P, Hamsten A, Eriksson P. Plasma interleukin (IL)-18 concentrations is elevated in patients with previous myocardial infarction and related to severity of coronary atherosclerosis independently of C-reactive protein and IL-6. Atherosclerosis 2006; 188: 450-4.

9. Ridker PM, Danielson E, Fonseca FA, et al. Rosuvastatin to prevent vascular events in men and women with elevated C-reactive protein. N Engl J Med 2008; 359: 2195-207.

10. Lindahl B, Toss H, Siegbahn A, Venge P, Wallentin L. Markers of myocardial damage and inflammation in relation to long-term mortality in unstable coronary artery disease. FRISC Study Group. Fragmin during Instability in Coronary Artery Disease. N Engl J Med 2000; 343: 1139-47.

11. Burke AP, Tracy RP, Kolodgie F, et al. Elevated C-reactive protein values and atherosclerosis in sudden coronary death: association with different pathologies. Circulation 2002; 105: 2019-23.

12. Yip HK, Sun CK, Chang LT, Wu CJ. Strong correlation between serum levels of inflammatory mediators and their distribution in infarct coronary artery. Circ J 2006; 70: 838-45.

13. Genest J. C-reactive protein: risk factor, biomarker and/or therapeutic target? Can J Cardiol 2010; 26: 41A-44A. (Review)

14. Stein JH, McBride PE. Hyperhomocysteinemia and atherosclerotic vascular disease: pathophysiology, screening, and treatment. off. Arch Intern Med 1998; 158: 1301-6. (Review)

15. Medina MA, Amores-Sánchez MI. Homocysteine: an emergent cardiovascular risk factor? Eur J Clin Invest 2000; 30: 754-62. (Review)

16. Knekt P, Reunanen A, Alfthan G, et al. Hyperhomocystinemia: a risk factor or a consequence of coronary heart disease? Arch Intern Med 2001; 161: 1589-94.

17. Ueland PM, Refsum H, Stabler SP, Malinow MR, Andersson A, Allen RH. Total homocysteine in plasma or serum: methods and clinical applications. Clin Chem 1993; 39: 1764-79. (Review)

18. Chua S, Wu CJ, Chang HW, et al. Impact of elevated plasma total homocysteine concentration on coronary atherosclerosis in Chinese patients with acute myocardial infarction undergoing primary coronary intervention. Int Heart J 2005; 46: 181-93.

19. Hermiller JB, Cusma JT, Spero LA, Fortin DF, Harding MB, Bashore TM. Quantitative and qualitative coronary angiographic analysis: review of methods, utility, and limitations. Cathet Cardiovasc Diagn 1992; 25: 110-31. (Review)

20. Danesh J, Lewington S. Plasma homocysteine and coronary heart disease: systematic review of published epidemiological studies. J Cardiovasc Risk 1998; 5: 229-32.

21. Schnyder G, Roffi M, Flammer Y, Pin R, Hess OM. Association of plasma homocysteine with restenosis after percutaneous coronary angioplasty. Eur Heart J 2002; 23: 726-33.

22. Bostom AG, Silbershatz H, Rosenberg IH, et al. Nonfasting plasma total homocysteine levels and all-cause and cardiovascular disease mortality in elderly Framingham men and women. Arch Intern Med 1999; 159: 1077-80.

23. Kark JD, Selhub J, Adler B, et al. Nonfasting plasma total homocysteine level and mortality in middle-aged and elderly men and women in Jerusalem. Ann Intern Med 1999; 131: 321-30.

24. Antoniades C, Antonopoulos AS, Tousoulis D, Marinou K, Stefanadis $\mathrm{C}$. Homocysteine and coronary atherosclerosis: from folate fortification to the recent clinical trials. Eur Heart J 2009; 30: 6-15. (Review)

25. Anderson JL, Muhlestein JB, Horne BD, et al. Plasma homocysteine predicts mortality independently of traditional risk factors and C-reactive protein in patients with angiographically defined coronary artery disease. Circulation 2000; 102: 1227-32.

26. Folsom AR, Nieto FJ, McGovern PG, et al. Prospective study of coronary heart disease incidence in relation to fasting total homo- 
cysteine, related genetic polymorphisms, and B vitamins: the Atherosclerosis Risk in Communities (ARIC) study. Circulation 1998; 98: 204-10.

27. Nygård O, Nordrehaug JE, Refsum H, Ueland PM, Farstad M, Vollset SE. Plasma homocysteine levels and mortality in patients with coronary artery disease. N Engl J Med 1997; 337: 230-6.

28. Ueland PM, Refsum H. Plasma homocysteine, a risk factor for vascular disease: plasma levels in health, disease and drug therapy. J Lab Clin Med 1989; 114: 473-501. (Review)

29. García-Tevijano ER, Berasain C, Rodríguez JA, et al. Hyperhomocysteinemia in liver cirrhosis: mechanisms and role in vascular and hepatic fibrosis. Hypertension 2001; 38: 1217-21.

30. Kaye JM, Stanton KG, McCann VJ, et al. Homocysteine, folate, methylene tetrahydrofolate reductase genotype and vascular morbidity in diabetic patients. Clin Sci (Lond) 2002; 102: 631-7.

31. Stein JH, Bushara M, Bushara K, McBride PE, Jorenby DE, Fiore MC. Smoking cessation, but not smoking reduction, reduces plasma homocysteine levels. Clin Cardiol 2002; 25: 23-6.

32. Hoogeveen EK, Kostense PJ, Jakobs C, et al. Hyperhomocysteinemia increases risk of death, especially in type 2 diabetes: 5-year follow-up of the Hoorn Study. Circulation 2000; 101: 1506-11.
33. Pitla S, Nagalla B. Gender-related differences in the relationship between plasma homocysteine, anthropometric and conventional biochemical coronary heart disease risk factors in middle-aged Indians. Ann Nutr Metab 2009; 54: 1-6.

34. Graham IM, Daly LE, Refsum HM, et al. Plasma homocysteine as a risk factor for vascular disease. The European Concerted Action Project. JAMA 1997; 277: 1775-81.

35. Gaede P, Vedel P, Larsen N, Jensen GV, Parving HH, Pedersen O. Multifactorial intervention and cardiovascular disease in patients with type 2 diabetes. N Engl J Med 2003; 348: 383-93.

36. Vittinghoff E, Shlipak MG, Varosy PD, et al. Risk factors and secondary prevention in women with heart disease: the Heart and Estrogen/progestin Replacement Study. Ann Intern Med 2003; 138: $81-9$.

37. Grundy SM, Cleeman JI, Merz CN, et al. Implications of recent clinical trials for the National Cholesterol Education Program Adult Treatment Panel III guidelines. Circulation 2004; 110: 22739. (Review)

38. Pencina MJ, D'Agostino RB Sr, Larson MG, Massaro JM, Vasan RS. Predicting the 30-year risk of cardiovascular disease: the framingham heart study. Circulation 2009; 119: 3078-84. 